NBER WORKING PAPER SERIES

\title{
FORCED OUT OF THE CLOSET: \\ THE IMPACT OF THE AMERICAN INVENTORS PROTECTION ACT ON THE TIMING OF PATENT DISCLOSURE
}

\author{
Daniel K.N. Johnson \\ David Popp \\ Working Paper 8374 \\ http://www.nber.org/papers/w8374 \\ NATIONAL BUREAU OF ECONOMIC RESEARCH \\ 1050 Massachusetts Avenue \\ Cambridge, MA 02138 \\ July 2001
}

The authors would like to thank Adam Jaffe, Bronwyn Hall, Josh Lerner, Jenny Lanjouw, Ariel Pakes, participants of the 1999 NBER Summer Workshop on Patents and Public Policy and two anonymous referees for helpful comments, Mohamed Hassan for valuable research assistance, and Jim Hirabayashi of the U.S. Patent Office for his assistance in providing data and his patience in answering our many questions. Despite their assistance, any remaining errors are the responsibility of the authors. We are grateful to the University of Kansas New Faculty General Research Fund and a Wellesley College Faculty Grant for financial support. The views expressed herein are those of the authors and not necessarily those of the National Bureau of Economic Research.

(C) 2001 by Daniel K.N. Johnson and David Popp. All rights reserved. Short sections of text, not to exceed two paragraphs, may be quoted without explicit permission provided that full credit, including $\subset$ notice, is given to the source. 
Forced Out of the Closet:

The Impact of the American Inventors Protection Act on the Timing of Patent Disclosure

Daniel K.N. Johnson and David Popp

NBER Working Paper No. 8374

July 2001

JEL No. O34, O38

\begin{abstract}
$\underline{\text { ABSTRACT }}$
Beginning in November 2000, patent applications filed in the United States are disclosed after 18 months, rather than when the patent is granted. Using U.S. patent data from 1976-1996, we find that major inventions are most likely to be affected, as they take longer to go through the application process. We provide evidence that this change will result in faster knowledge diffusion, and conclude with a simulation of the law's potential effect on patent grants.
\end{abstract}

Daniel K.N. Johnson

Department of Economics

Pendleton East

Room 309

Wellesley College

106 Central Street

Wellesley, MA 02481-8260

Tel: 781-283-2236

Fax: 781-283-2177

djohnson@wellesley.edu

http://www.wellesley.edu/Economics/johnson

\author{
David Popp \\ Department of Public Administration \\ Center for Environmental Policy Administration \\ Center for Technology and Information Policy \\ The Maxwell School \\ Syracuse University \\ 400 Eggers Hall \\ Syracuse, NY 13244-1090 \\ and NBER \\ Tel: 315-443-2482 \\ Fax: 315-443-1075 \\ dcpopp@maxwell.syr.edu \\ http://faculty.maxwell.syr.edu/dcpopp/index.html
}




\section{Forced Out of the Closet: The Impact of the American Inventors Protection Act on The Timing of Patent Disclosure}

In practically every industrialized country, patent applications are made public 18 months after the application is filed. This is true whether the patent has been granted or is still in the application process. Until recently, the one exception was the United States. Historically, information on a U.S. patent application has not been published until the patent is granted. If the patent is never granted, the information is never made public. However, the American Inventors Protection Act of 1999 (P.L. 106-113), enacted on November 29, requires that U.S. patent applications be made public 18 months after the initial application is filed. ${ }^{1}$ This paper will analyze the likely impact of the change in disclosure laws on the U.S. patent system.

Proponents of this change offer several reasons for their support. One, of course, is that it will move towards international harmonization of patent law, in the spirit of the World Trade Organization. Second, disclosure of patent applications will make information about new technologies publicly available more quickly, thus speeding the diffusion of knowledge and avoiding duplication of R\&D by different firms. Third, early disclosure will end the practice of "submarine patents" - patent applications that drag on for several years and are finally revealed after the technology has been widely adopted. Currently, patent applicants can purposely delay processing by filing for continuances and divisions of an initial application. After the patent is

\footnotetext{
${ }^{1}$ The publication requirement took effect on November 29, 2000. Since the goal is to harmonize U.S. patent law with that of other nations, an exception is provided for American inventors who sign an agreement not to apply for patent protection abroad. Information on the American Inventors Protection Act is from the U.S. Patent Office web site at: http://www.uspto.gov/web/offices/dcom/olia/aipa/summary.htm.
} 
finally granted, the patent holder can collect royalties from unsuspecting users of the technology. ${ }^{2}$ Early disclosure of all patent applications would make "submarine patents" impossible.

Opponents of the change include 26 Nobel Laureates who wrote an open letter to the U.S. Senate against early disclosure, stating that it "could result in lasting harm to the United States and the world." ${ }^{3}$ The Nobel Laureates offer two main arguments. First, they argue that early disclosure will be most harmful to "small inventors and thereby discourage the flow of new inventions that have contributed so much to America's superior performance in the advancement of Science and Technology." They argue that the patents most affected by early disclosure are breakthrough inventions, often made by independent inventors, that often take a long time to go through the patent process. As a result, independent inventors have lobbied against the change in disclosure laws, expressing concern that the new law aids corporations at the expense of independent inventors. (The Economist, 1997). Second, the Nobel Laureates argue that the new rules would weaken the value of patent protection for these breakthrough inventions. The concern is that more inventors will choose to keep such inventions secret, thus slowing the diffusion of knowledge represented in these inventions.

Despite the importance of the patent application disclosure issue, very little has been written about it in the economics literature. The existing papers on the disclosure of patent applications are all theoretical in nature. Most significantly, Aoki and Spiegel (1998) find that early disclosure leads to fewer patent applications and fewer innovations. For a given number of innovations, consumer surplus increases, because early disclosure increases the probability of

\footnotetext{
${ }^{2}$ The most famous example of "submarine patents" are the patents held by Jerome H. Lemelson for robotic equipment on assembly lines. He filed the initial applications in the 1950's, but delayed the process by filing continuances and altering his designs. The patents finally emerged in the 1980's, after the techniques he patented had been used for years by manufacturers who had no knowledge of his pending applications. Lemelson was able to collect royalties from these manufacturers. (Montgomery, 1998)
} 
new technologies reaching the market. However, they offer the caveat that the level of innovation may fall because of the decreased value of patent protection. ${ }^{4}$

In this paper, we use data on United States patents from 1976-1996 to study some of the possible effects of early disclosure. First, we use patent citation data to test the hypothesis that patents that take longer to go through the application process are more significant inventions. We see that such patents are cited more frequently, suggesting that these patents contribute more to future researchers than the average patent. Having shown this, we look at the rates of diffusion of citation to ascertain the increased benefits of early disclosure that come from faster diffusion of knowledge. We conclude with a simulation of the possible effect of early disclosure on patenting activity in the United States, finding some evidence of positive short-run but negligible long-run effects.

\section{Institutional Details: Laws and Citations}

Until passage of the American Inventors Protection Act of 1999 (P.L. 106-113), the United States was unusual in allowing patent applications to remain secret until granted. The Act includes a requirement that U.S. patent applications be disclosed 18 months after the initial application, unless the inventor signs an agreement to forego patent protection in other countries. To better understand how the decision to publish patent applications before they are granted

3 A link to the letter can be found on the home page of the author, at http://www.wellesley.edu/Economics/johnson/links.html.

${ }^{4}$ Other theoretical models of patent application disclosure include Aoki and Prusa (1996) and Bloch and Markowitz (1996). Aoki and Prusa's paper helps explain why large U.S. corporations have come out in support of early disclosure while small inventors and several economists have argued against it. Their model predicts that early disclosure should lead to inventions that make smaller improvements in quality, but that firms should make higher profits with early disclosure, as they are able to coordinate their R\&D efforts. Finally, Ordover (1991) notes that disclosure of patent applications is an important difference between patenting systems in Japan and the U.S., as Japan's early disclosure helps to induce cooperation among firms. 
might influence innovative activity, we must first discuss the legal implications of such a change in policy.

The date on which a patent application is first filed in any nation is its priority date. Inventors who wish protection in multiple nations may either file separate applications in each nation, or they may file a Patent Cooperation Treaty (PCT) application and designate which member nations (112 currently listed) to incorporate in the petition. Patent rights are protected only in those nations where granted (i.e. a PCT application need not be effective in all designated nations, as granting decisions are still made by the local patenting offices) but where rights are granted, protection begins (retroactively) at the priority date if applications were filed within one year of that date. Otherwise, protection extends only from the date on which each individual national application (or PCT application) is filed. Prior to the American Inventors Protection Act of 1999, only the contents of an application for patent protection in countries other than the U.S. were published 18 months after filing. For US inventors filing abroad, this meant that applications would be published within a maximum of 30 months after the priority date in the U.S.

As a patent is examined, changes may be made to it. ${ }^{5}$ For example, the patent examiner may determine that an application contains too many claims to be considered in a single patent. The applicant is given the choice to abandon the original application and file a new, modified version of the original application. As long as the new application is filed on the same day as the original application is withdrawn, it is labeled a continuation of the original application and given the same priority date as the first application. If the continuation also includes new

\footnotetext{
${ }^{5}$ The information in this paragraph comes form Blount (1999) and correspondence with the U.S. Patent Office.
} 
elements, it is labeled as a "continuation in part." As long as the new claims are substantially related to the original ones, the applicant can keep the original priority date.

Figure 1 gives an example of a patent that has been through several modifications. Note that the application date listed on the front page of the patent, March 13, 1989, is the application date of the most recent version. However, under related application data, we see that this patent is a division and a continuation in part of several earlier patent applications. The earliest related application date (December 30, 1981) would be the priority date for this patent. Protection would be guaranteed from that date, even though the application directly related to this patent wasn't filed until 1989, and the patent wasn't granted until 1991.

Submarine patents take advantage of the potential modifications that may be made to a patent. The applicant begins by filing a patent with broad claims, followed by a series of continuing applications to keep the patent submerged in the patent office for several years. Once a product infringes on the application, the applicant "surfaces" the patent, allowing the patent to be issued. Since protection is guaranteed from the priority date, which comes from the first related patent application, the patent holder can claim infringement on the patent for inventions that occurred since the priority date, even though the inventors of the infringing products were unaware of the pending patent application (Blount, 1999).

Although submarine patents received much attention during the debate on early disclosure in Congress, in practice they do not appear to be a significant problem. During testimony to Congress, former U.S. Patent Office Commissioner Bruce Lehman testified that only 627 patents issued from 1971-1993 fit the definition of a submarine patent. Of these, $41 \%$ were held by the U.S. government and kept secret for security reasons, and 75 were private patents ordered to be kept secret for security reasons. Thus, only 182 patents, or $0.00028 \%$ of the 
over 2 million patents granted in that time frame, were truly submarine patents. Furthermore, since the Uruguay Round of GATT in 1995, patent protection in the U.S. extends 20 years from the filing date, as opposed to the previous coverage of 17 years from the date of grant. As a result, indefinitely long submarine patents are no longer possible, even without changing U.S. patent law towards earlier disclosure of applications (Blount 1999). ${ }^{6}$

\section{Do Major Innovations Take Longer To Go Through The Patent Process?}

Having ruled out the potential benefit of eliminating submarine patents, we proceed to examine the other pros and cons of early disclosure. First, we test the hypothesis that more valuable patents take longer to go through the granting process. If this is the case, as opponents of early disclosure argue, mandating publication of patent applications after 18 months may discourage major inventions.

There are a number of interesting strands of literature that explore how to measure the value of a patent, presented thoughtfully by Lanjouw et al. (1996). Commercial value is probably best captured using renewal data about individual patents, since a fee is usually required to keep a patent in force after the initial grant (see for example, Pakes and Simpson 1989), and a firm will be more likely to pay the renewal fee for more valuable patents. Putnam (1996) extends this idea to include information about international protection, where the costs of filing in separate nations are incorporated to form more precise measures of value. Once again, inventors of more valuable patents are more willing to bear the costs of filing for protection in multiple countries.

\footnotetext{
6 However, the U.S. legal system continues to recognize the rights of the "first to invent" a product or process, rather than the "first to file" an application for protection. Protection of this type frees inventors from the need to obtain a priority date by applying for a patent, as long as they adequately document the date of invention for future infringement lawsuits. This course of action does not qualify as a submarine patent (as it never submerged), although it has a similar impact on subsequent inventors, and is completely unaffected by the American Inventors
} 
Our focus on the value of patents is slightly different, since our interest lies in the social value of a patent, or its ability to create inspiration for future invention. Hence, our measure of the size of an invention is based on subsequent citations, with no claims made about their commercial viability or financial value. When a patent is granted, it contains citations to earlier patents that are related to the current invention. These citations are analogous to references in a journal article, conveying a list of ideas that the inventor may have accessed during the inventive process. It is the applicant's responsibility to list any related previous patents of which he or she is aware, and the examiner, who specializes in just a few patent classifications, will add other patents to the citations as well as subtracting any irrelevant patents cited by the inventor. Patent citations narrow the scope of a new patent by placing cited patents outside the realm of the current patent, so it is important for the legal system that all relevant patents be included in the citations. $^{7}$

The key assumption here is that a citation made to a previous patent indicates a flow of knowledge from the cited patent to the citing patent, so that patents cited more frequently are considered more valuable to future inventors. ${ }^{8}$ Jaffe, Fogarty, and Banks (1998) investigate the validity of this claim, using evidence from citations made to NASA patents. They conclude that, although there is noise in the citation process $^{9}$, aggregate citation patterns represent knowledge

Protection Act of 1999.

7 "Outside the realm" means that a patent holder cannot file an infringement suit against someone whose invention infringes on qualities also included in cited patents.

${ }^{8}$ The relationship between citations and value was first shown by Trajtenberg (1990). Other influential work on patent citations includes research by Adam Jaffe and his co-authors, such as Jaffe, Fogarty, and Banks (1998), Jaffe and Trajtenberg (1996), Caballero and Jaffe (1993), and Jaffe, Henderson, and Trajtenberg (1993).

${ }^{9}$ For example, while researching a patent claim, a patent attorney or patent examiner may uncover a related patent that the inventor honestly knew nothing about. Nonetheless, due to the legal importance of patent citations, such a patent would need to be cited. In interviews with patent attorneys, Jaffe, Fogarty, and Banks (1998) find that patent attorneys prefer to "play it safe" and cite patents that are related even if the inventor does not have direct knowledge of the invention. In fact, our data set contains 82,712 cases of citations made by patents whose initial application date is before the initial application date of the cited patent. These citations make up $1.3 \%$ of our sample. 
spillovers, although the spillover may be indirect. Similarly, Lanjouw and Schankerman (1999) explore several measures of patent quality, including citations, the number of claims on the patent, and renewals, and find citations made by subsequent patents to be the least noisy indicator of patent value. ${ }^{10}$ Thus, we investigate whether patents with long grant lags are cited more frequently.

\section{A. Data}

For the citation analysis, we use data on all patents granted in the United States from 1976-1996. After removing patents with clearly erroneous data (such as application dates after the grant date), the data sample includes $1,653,992$ patents. The main source of the data was a set of CD-ROM's from MicroPatent, which include all information available on the front page of a patent, including the dates of grant and application. Because disclosure of a patent application would occur 18 months after the first related patent application, we supplemented the MicroPatent data with data on related applications provided by the U.S. Patent Office. ${ }^{11}$ Based on the classification given on the front page of the patent, we divided patents into six technology groups: Medical/Biochemistry, Other Chemical, Electronics, Mechanical, Engineering/Physics, and Other Technologies.

Summary statistics for the lag, in months, between patent application and the granting of the patent (the grant lag) are given in Table 1. For each technology group, the first column of data provides statistics for all patents in the sample, and the second column provides statistics for domestic applications only. In each case, the mean lag is about 28 months, but this varies by technology group. Also, note that the mean lag is slightly larger for domestic patents. The mean

\footnotetext{
${ }^{10}$ Lanjouw and Schankerman note that their definition of patent quality includes both the value of the patent to the firm and the technological opportunity represented in the patent. Thus, their measure encompasses both of the values discussed here.
} 
lag is largest for medical/biochemistry patents, which have a mean grant lag of 35 months. Also, as Figure 2 shows, the distributions of grant lags are quite skewed. The median lag ranges from 21 to 28 months, while the most common grant lag is 20 months.

For the analysis in this paper, we focus on domestic patent applications - that is, United States patents that have been granted to American applicants - of which there are 930,059 in our data set. Since patent laws vary throughout the world, the value of patent protection varies as well, so using only domestic patent applications avoids those exogenous factors. In addition, foreign applicants of U.S. patents are likely to have filed in their home country first. Because patent applications in other nations are disclosed after 18 months, applicants who have filed for patent protection elsewhere do not receive the same benefits from the secrecy of applications that U.S. applicants would, and would be affected differently by a change in disclosure laws in the United States. ${ }^{12}$

Note from Figure 2 that the distribution of grant lags shifts leftward when only domestic patent applicants are considered. The most frequent lag for patents with U.S. applicants is 17 months. Most importantly, only 30 percent of patents are granted within 18 months of their first related filing. Thus, most patents would lose some secrecy with the adoption of a requirement to publish all applications within 18 months of filing. Table 2 shows the percentage of patents granted within 18 months, between 19 and 30 months, and after 30 months for each technology group. Medical and biochemistry patents are most affected, as less than $20 \%$ of those patents are granted in 18 months or less.

If an applicant chooses to patent abroad, the foreign application is subject to disclosure 18 months after the foreign filing. Since the foreign filing usually occurs one year after the initial

\footnotetext{
${ }^{11}$ We thank Jim Hirabayashi for providing the related application data.
} 
domestic application (to maximize secrecy but assert priority under PCT), these patents would only lose one year's worth of secrecy, as the new law would disclose the application 18 months after US application, rather than 30 months later. In our data set, $30 \%$ of all domestic patents have grant lags greater than 30 months, so would be affected by the policy change if the applicant is considering international protection.

Our goal is to test whether patents most affected by the policy change (those that have longer grant lags) are more valuable in terms of subsequent citation, so we want to control for other causes of a long grant lag. As mentioned earlier, one reason that the application process may take so long is that some patents may experience modifications to the initial application. Often, this occurs when the initial patent application was too broad. For example, the patent examiner may feel that only some of the claims are truly patentable, creating a grant lag unrelated to the quality (or subsequent citability) of the remaining patentable ideas. The last two columns of Table 1 present a comparison of the grant lag for domestic patents with related applications versus those that have no amendments. The average grant lag for patents that do not have a related application is only 22.5 months, while the average for patents that have related applications is over twice as long, at 47.4 months. While only $25 \%$ of all applications have related applications, patents in the two chemical technology groups are most likely to use related applications. However, patents in these groups that do not use related applications still take longer to go through the application process than other patents, suggesting that research in the chemicals industry would experience the greatest effect of early disclosure.

Finally, note that the grant lag varies over time. Figure 3 shows how the grant lag varies by the year of the first related application for each granted patent. Note that the percentage of

\footnotetext{
${ }^{12}$ See footnote 28 for a discussion of the impact of the law on U.S. applicants filing for protection abroad.
} 
patents granted within 18 months falls during the late 1970 s before rebounding in $1983 .{ }^{13}$ The Ushaped trend is likely explained by the well-documented cutbacks in the patent office budget in 1979 that led to fewer patents being issued that year. ${ }^{14}$

\section{B. Modeling Of Citation Analysis}

As stated in the previous section, we focus on citations to all U.S. patents granted to domestic applicants between 1976 and 1996. However, citations made by patents with either domestic and foreign applicants are considered. To analyze patent citations, we use a model developed by Adam Jaffe and his co-authors (Caballero and Jaffe, 1993; Jaffe and Trajtenberg, 1996). The model estimates the likelihood that a patent, $k$, granted in year $t$ will be cited by a subsequent patent, $K$, granted in year $T$. Exponential rates of decay and diffusion model the flow of knowledge over time. So that we can use the results of the regression for our simulation in section IV we modify Jaffe's basic model so that decay occurs because new inventions make older patents obsolete, rather than simply over time. Thus, the probability can be written as:

$$
p(k, K)=\alpha(k, K) \exp \left[-\beta_{1}\left(\sum_{s=t}^{T} N_{s}\right)\right]\left[1-\exp \left(-\beta_{2}(T-t)\right)\right]
$$

where $\beta_{1}$ represents the decay rate, $\beta_{2}$ represents the rate of diffusion, and the summation represents the total number of patents granted from the year the cited patent was granted to the year the citing patent was granted. $\alpha(k, K)$ captures other attributes of patents $k$ and $K$ that affect the probability of citation. For example, in this paper we consider the grant lag of the patent as an attribute that may influence the probability of citation. Other factors include the computerization of patent office records, which makes finding related patents easier. As a result,

\footnotetext{
${ }^{13}$ Our data include patents granted through December 31, 1996. Thus the data are truncated, particularly for patents with applications in the early 1990s. Nonetheless, since few patents take more than five years to be granted, the rebound in application processing speed observed during the early 1980s and subsequent decrease in the mid 1980s
} 
there are more citations made by newer patents. To control for such factors, we include the following parameters in our model:

- the grant lag of the cited patent $\left(\alpha_{g}\right)$,

- whether or not the cited patent had a related application $\left(\alpha_{a}\right)$,

- the grant year of the cited patent $\left(\alpha_{t}\right)$,

- the technology group of the cited patent $\left(\alpha_{i}\right)$,

- the country of the citing patent $\left(\alpha_{j}\right)$, and

- the frequency by which patents granted in the citing year cite earlier patents $\left(\alpha_{T}\right)$.

Note that the model requires us to estimate attributes associated with the cited year, the citing year, and the lag between them. Because the age of patents enters the model non-linearly, it is possible to identify all three attributes. Although in theory it is possible to estimate such attributes for every citing and cited year, in practice the model does not converge to a solution when it is specified this way. As a result, citing and cited year attributes are grouped into twoyear intervals. In addition, since it is new knowledge in related fields that makes older knowledge obsolete, we use the number of patents that have occurred within technology group $i$ to model the decay rate. Finally, to identify the model, it is necessary to normalize one value of each parameter to $1 .^{15}$ Using these parameters, the probability of a patent $k$ granted in year $t$ being cited by a patent, $K$, granted in year $T$ can be estimated as:

$$
p_{k, K}=\alpha_{g} \alpha_{a} \alpha_{i} \alpha_{t} \alpha_{T} \exp \left[-\beta_{1}\left(\sum_{s=t}^{T} N_{i, s}\right)\right]\left\{1-\exp \left[-\beta_{2}(T-t)\right]\right\}+\varepsilon_{k, K}
$$

\footnotetext{
is not due to truncation.

${ }^{14}$ See Griliches (1990) for more on the Patent Office budget problems in 1979.

${ }^{15}$ The normalization is as follows: for the grant lag, $\alpha_{18}=1$, for related applications, $\alpha_{N o}=1$, for citing patents, $\alpha_{1977-}$ ${ }_{78}=1$, for cited patents, $\alpha_{1976-77}=1, \alpha_{U S}=1$ for the citing country, and for the technology groups, $\alpha_{\text {Other }}=1$.
} 
In this paper, the parameter of greatest interest to us is $\alpha_{g}$, which represents the likelihood that a patent with a given grant lag will be cited by subsequent patents. $\alpha_{18}$ is normalized to 1 . Thus, estimates of $\alpha_{g}$ greater than (less than) 1 indicate that patents with that grant lag are more (less) likely to be cited than patents with a grant lag of 18 months. The null hypothesis is that $\alpha_{g}$ will be greater than 1 for patents with a grant lag greater than 18 months.

\section{Estimation of the Citations Model}

Most patents are never cited. As such, if we estimate equation (2) for individual combinations of potential citing/cited patents, the dependent variable will be zero for most observations. Thus, following the earlier work of Jaffe and his coauthors, we group the patents into cohorts of potential citations. For cited patents, the relevant attributes are the year of grant, the technology group, whether or not the patent has a related application, and the lag between application and grant. For citing patents, the relevant attributes are the country of origin and the year of grant. For example, one cohort may be all patents granted in physics in 1976 that have a grant lag of 18 months, did not have a related patent application, and that are cited by patents granted in 1978 to American applicants. The expected number of citations to a cohort is just the likelihood of a single citation times the number of patents that are potentially cited or citing patents:

(3) $\mathrm{E}\left[C_{g, a, i, t, j, T}\right]=\left(N_{g, a, i, t}\right)\left(N_{j, T}\right) p_{k, K}$

$$
=\left(N_{g, a, i, t}\right)\left(N_{j, T}\right) \alpha_{g} \alpha_{a} \alpha_{i} \alpha_{t} \alpha_{j} \alpha_{T} \exp \left[-\beta_{1}\left(\sum_{s=t}^{T} N_{i, s}\right)\right]\left\{1-\exp \left[-\beta_{2}(T-t)\right]\right\}
$$

$C_{g, a, i, t, j, T}$ is the number of citations to the patent cohort of patents with or without related applications (a) granted in year $t$ in technology $i$ that have a grant lag of $g$ months made by patents with applicants from country $j$ granted in year $T . N_{g, a, i, t}$ is the number of patents with or 
without a related application granted in year $t$ in technology $i$ with a grant lag of $g$ (the potentially cited patents), and $N_{j, T}$ is the number of patents granted in year $T$ (the potentially citing patents). Defining $p_{g, a, i, t, j, T}$ as the probability that a patent in cohort $g, a, i, t$ is cited by a patent in cohort $j, T$, equation (3) can be re-written as:

(4) $p_{g, a, i, t, j, T}=\frac{C_{g, a, i, t, j, T}}{\left(N_{g, a, i, t}\right)\left(N_{j, T}\right)}=\alpha_{g} \alpha_{a} \alpha_{i} \alpha_{t} \alpha_{j} \alpha_{T} \exp \left[-\beta_{1}\left(\sum_{s=t}^{T} N_{i, s}\right)\right]\left[1-\exp \left(-\beta_{2}(T-t)\right]+\varepsilon_{g, a, i, t, j, T}\right.$, which can be estimated by non-linear least squares as long as the error term, $\varepsilon_{g, a, i, t, j, T}$ is wellbehaved. Because the data are grouped, we weight each observation by $\sqrt{\left(N_{g, a, i, t}\right)\left(N_{j, T}\right)}$ to avoid problems with heteroskedasticity (Greene 1993). ${ }^{16}$

Three versions of equation (4) are estimated. First, patents are simply divided into two groups: those with grant lags less than or equal to 18 months and those with grant lags greater than 18 months. Only the second group would be affected by the new law. $\alpha_{g}$ is normalized to 1 for patents with grant lags less than or equal to 18 months. The results of this regression are shown in Table 3. Most importantly, note that patents with grant lags greater than 18 months are 21 percent more likely to be cited than patents with shorter grant lags. This suggests that the patents that would be affected by changing disclosure laws in the United States are more valuable (more cited) patents. Results for the year effects, citing country, and the technology group are similar to results found by Jaffe and others, except that the citing year effects decline over time and medical patents appear more important ${ }^{17}$. One result of note is the set of rising estimates for

\footnotetext{
${ }^{16}$ In this regression, weighting is not only appropriate to get the correct standard errors, but also to get the correct parameter estimates. Because there are large variations in the size of the cohorts - in particular, because the cohorts for short grant lags are much smaller than other cohorts - an unweighted regression puts too much weight on these cohorts, which affects the estimate of the grant lag parameter.

${ }^{17}$ The citing year effects differ because our estimation includes more detailed grouping of the citing and cited years. Because Jaffe's data includes cited patents from 1963 forward, he groups the cited patent years into five year intervals. If the same specification is used here, we get results similar to Jaffe's earlier work for the citing year
} 
the year cited effect. This result could be seen as supporting the notion of an upswing in the productivity of R\&D during that period, as it suggests the research patented in these years was of greater use to future inventors. ${ }^{18}$ Also, as predicted, patents with related applications are 30 percent less likely to be cited, since their grant lags have been lengthened for administrative reasons, and are thus less useful to future inventors than patents of similar lag without related applications. $^{19}$

The second regression (see Table 4) shows the same result in greater detail, ${ }^{20}$ combining patents into eight grant lag groups. Note that the probability of citation increases with grant lags up to five years, with the biggest marginal effect coming in years two and three. This can be seen more clearly in Figure 4, which presents the results from a third regression. Here, we include all patents with a grant lag of 6 months or less in one group, all patents with a grant lag greater than 5 years in another, and include separate observations for all intervening grant lags by month. Figure 4 plots the $\alpha_{g}$ parameters from this regression against the grant lag in months. The bars represent plus/minus one standard deviation. Recall that the parameter for this effect was normalized to 1 for a grant lag of 18 months. Patents with a longer grant lag are affected by the policy change and, in all cases, such patents are more likely to be cited than a patent with an 18 month grant lag. Furthermore, patents with a grant lag less than 18 months are less likely to be

effects. However, we are concerned that the more aggregate grouping loses some information, as using it leads to unstable results in the experiments that follow in section III. Thus, we present the more detailed results described above.

${ }^{18}$ For a discussion on the returns to R\&D over time, see Kortum and Lerner (1998) and Popp (1997). Of course, the rising pattern of citing behavior should not be seen as definitive evidence of increasing productivity of R\&D, as it could be caused by other factors, such as computerization of records making it easier to identify more recent patents for citation.

${ }^{19}$ Of course, patents with related applications also have longer grant lags. Nonetheless, if we re-run the regression without the related application dummy variable, patents with grant lags greater than 18 months are still 10 percent more likely to be cited.

${ }^{20}$ Table 4 only shows the results for the grant lag parameters. The other results are similar to those reported in Table 3 , and are available from the authors upon request. 
cited. This result is statistically significant at the one percent level for all patents with grant lags between 8 and 16 months. ${ }^{21}$ Note that the effect of the grant lag tends to level off after approximately three years. The plateau that occurs is the result of related patent applications comprising a greater share of the patents with long grant lags. Nonetheless, the combined effect of higher probability of citation for long grant lags and lower probability of citation for related applications still results in these patents being cited more often. This is shown by the dashed line in Figure 4, which shows the results of a regression omitting the related application dummy variable. Here, the probability of citation plateaus approximately 20 percent above the probability of citation for patents with the 18-month grant lag. These results suggest that more valuable (highly cited) patents will be those most affected by early disclosure, supporting the argument made by opponents of early disclosure.

\section{Does Publication Lead to Disclosure?}

The primary gain from early disclosure is that it may speed the rate at which new information is diffused, which has two potential benefits. First, by making other researchers aware of current projects, less duplication of R\&D efforts would occur (Aoki and Prusa 1996). The second benefit stems from our results in the previous section. Since patents that are cited more frequently take longer to go through the application process, early disclosure can speed the rate at which the more useful inventions become public knowledge. This, in turn, should improve the quality (and quantity) of subsequent R\&D.

To study the potential gains from faster diffusion, we ask whether public disclosure of a patent application is the primary means used to disseminate knowledge. Publication of a patent is just one way that researchers learn about new ideas. Others include scientific publications,

\footnotetext{
${ }^{21}$ Because the attribute parameters enter the regression multiplicatively, the null hypothesis of no effect occurs when
} 
research conferences, and personal contact among inventors. ${ }^{22}$ If knowledge diffuses primarily via forms of disclosure other than through the publication of patent applications, early disclosure of patent applications would have a minimal effect on diffusion rates.

To test the importance of the publication of a patent to knowledge diffusion, we run a revised form of the probability of citation regression in equation (4). We estimate separate rates of decay and diffusion for patents with grant lags less than or equal to 12 months and for patents with grant lags greater than 24 months. If the actual publication of a patent is important to the dissemination of knowledge, then the rates of decay and diffusion should be the same for both. However, other activities that disseminate knowledge can take place as soon as the idea exists (that is, at the time of the patent application). If these activities are disseminating knowledge before the patent is granted, the apparent rate of diffusion should be faster for patents with longer grant lags, as much of the activity done to disseminate the information will have occurred before the patent is granted.

The intuition behind the test is shown in Figure 5. Figure 5 compares the actual time of diffusion to what is observed in the data. Each line represents a timeline from the date of application. The dark bar represents the actual diffusion, and the observed diffusion is denoted with brackets. Figure 5 considers two patents: one with a grant lag of 18 months, and a second with a grant lag of 36 months. Actual diffusion activity is assumed to take the same amount of time for each patent.

Case A shows what is observed when diffusion begins after publication of a patent. For simplicity, we assume that in each case diffusion lasts for 2 years after publication. Since we

\footnotetext{
the parameter equals 1 , rather than 0 .

${ }^{22}$ See Jaffe, Fogarty, and Banks (1998) for a more detailed exposition of how knowledge flows among researchers, and the role that patent citations play in the flow of knowledge.
} 
estimate diffusion based on the date of publication, 2 years is also the estimated period of diffusion. Case B shows what is observed if diffusion begins at application. The length of actual diffusion (the dark bar) is set so that observed diffusion (diffusion that occurs after the publication of the patent) equals 2 years for the "standard" patent with an 18-month grant lag. In this case, the period of diffusion observed based on the date of publication is just 6 months for the patent with the longer grant lag. Using data based on the date of grant, the period of diffusion appears faster for the second patent. ${ }^{23}$

Table 5A presents the results for the rates of decay and diffusion (other parameter estimates are similar to those found in section II. ${ }^{24}$ ) Note that there are small differences in the rates of decay and diffusion for patents with longer grant lags. The $F$-statistic for the null hypothesis that the rates of diffusion are equal and that the rates of decay are equal is 29.84 , leading us to reject the null hypothesis that the rates are equal. ${ }^{25}$ However, when we calculate the period of maximum diffusion, we see that the estimated periods of diffusion do not differ much. The maximum period of diffusion occurs after 4.6 years for the patents with short grant lags, and after 4.9 years for the patents with long grant lags.

The fact that the period of diffusion is longer for the patents with long grant lags is somewhat surprising, and occurs because the rate of decay is lower for these patents - suggesting

\footnotetext{
${ }^{23}$ Since the conclusion that publication matters is found by observing no change in the estimated period of diffusion, an important concern is whether, given the specification of our model, the estimated rates of decay and diffusion really would change if the period changed. To test this, we performed the following experiment. First, we estimated the rates of decay and diffusion for patents with grant lags of 12 months or less. Based on these estimates, the probability of citation reaches a maximum after 4.25 years. Then, we added two years to the grant date on these patents, to pretend that they had a long grant lag, rather than a short grant lag. For these patents, we know that diffusion started earlier than the new "grant date," since the actual grant date occurred two years earlier. When we estimate the rates of decay and diffusion for the redated patents, the maximum probability of citation occurs at 2.4 months - 22 months earlier than the correctly dated patents, suggesting that the rates of decay and diffusion will change if diffusion occurs before publication. We thank an anonymous referee for suggesting this experiment.

${ }^{24}$ For this regression, the specification with detailed grant lags, used for Figure 4, was used.

${ }^{25}$ The critical value at the $95 \%$ level is 3.00 .
} 
that these patents, because they are of higher quality, decay more slowly. To adjust for this, we repeat the above experiment allowing only the rate of diffusion to vary. These results are shown in Table 5B. In this case, the estimated rates of diffusion are statistically indistinguishable from one another. In each case, the period of maximum diffusion is 4.9 years.

These results suggest that the diffusion process indeed begins with the publication of the patent. Early disclosure will therefore have important beneficial effects for researchers. Note that this finding provides ammunition for both sides of the debate over early disclosure. It suggests that publication will offer the benefit of faster diffusion of knowledge. However, it also suggests that early disclosure will hurt inventors, by allowing others to learn of their inventions faster, and thus potentially invent around them more quickly.

Table 6 provides an idea of how large the gain of knowledge disclosure may be, presenting the weighted average months of disclosure gained domestic patent applications in each technology group. This ranges from an additional 28 months of disclosure for patents in engineering and physics to just over 8 months of additional disclosure for other technology groups. The overall weighted average for domestic patents is nearly 12 months.

\section{Simulating Early Disclosure}

This soon after the policy change, it is impossible to determine how inventors will react to the shift. Firms might decide to withhold information from their competitors by keeping trade secrets instead of applying for patents, leading to less public information for future inventors to use, with cumulatively dampening effects over time. In this section, we simulate a "what-if" or best-case scenario, looking for the gains from faster diffusion that could result from the new policy if nothing else changed (including the propensity to patent), then asking whether a small 
behavioral shift could negate these potential gains.

To simulate the maximum potential gains from faster diffusion, we first use patent data from 1900 to 1998 to establish a baseline predicted level of patenting activity until 2040. For this, we regress patents in year $t$ on a stock of cumulative knowledge, weighted by past citations $^{26}$. Defining $N_{g, t}$ as the number of patents with grant lag g that were granted in year $t$, and $K_{T}$ as the stock of knowledge in year $T$, we have:

$$
K_{T}=\sum_{g} \sum_{t=0}^{T} \alpha_{g} N_{g, t} \exp \left[-\beta_{1}\left(\sum_{s=t}^{T} N_{g, s}\right)\right] \exp \left[-\beta_{2}(T-t)\right]
$$

where $\alpha_{g}$ is the weight for patents of each grant lag and $\beta_{1}$ and $\beta_{2}$ are the rates of decay and diffusion estimated in section II. We use an exponential form for the regression, which yields the following results [standard errors in brackets]: ${ }^{27}$

$$
\begin{aligned}
& N_{t}=\exp \left(a+b K_{t}+c K_{t}^{2}\right) \\
&=\exp \left(12.48-0.39 K_{t}+0.02 K_{t}^{2}\right) \\
& {[0.53][0.14] \quad[0.01] }
\end{aligned}
$$

Figure 6 shows the actual patent data from 1900-1998, the predicted values of the regression for each year, as well as simulated data until $2040 .^{28}$

Figure 6 also shows the results of our best-case policy simulation, with the policy change effective in November 29, 2000. On that date, the information in patent applications will be disclosed 18 months after filing, rather than when the patent is granted. As a result, the stock of

\footnotetext{
${ }^{26}$ To avoid bias in knowledge stocks due to patents with related applications (which are significantly less cited than the patent cohort sharing the same lag, and are almost exclusively in cohorts with long lags), we estimated the probability of subsequent citation for patents with related applications, then separately for patents without related applications, taking the weighted average of those probabilities for each grant lag.

${ }^{27}$ Various forms of the following baseline regression were tried, including quadratic and linear functions, basing the decay of knowledge on time, rather than accumulated patents, regressions using a time trend, and structural changes over time (e.g. permitting the coefficients to change in 1982 with the change in patent law and patent activity). The simulation results below were robust to the various specifications. We use the current specification because it best replicated the actual patent data over the $20^{\text {th }}$ century, with an average annual error of 2.6 percent.

${ }^{28}$ The simulated data use the predicted values from 1900 to 1998 as the knowledge stock.
} 
knowledge on which inventors can build is larger in subsequent years, as it includes patents with priority dates before November 29, 2000 that are published when granted, as well as patent applications filed after that date which are published 18 months after the priority date.

The optimistic policy simulation line in Figure 6 shows two salient features. First, there is a sudden rise in the number of patents granted immediately after the policy change. As submitted applications are published more quickly than before, they enter the public domain with an immediate effect on subsequent knowledge creation, speeding up following innovations. The second, and perhaps more striking, feature of the simulation is that this impact of policy on patenting activity is not permanent. Due to the estimated rates of diffusion and decay of knowledge, the level of patents per year stabilizes within thirty years. In fact, the baseline and the policy-impacted series are virtually identical fifty years after inception.

Of course, the above simulation simply predicts future patents based on past trends, assuming no change in other factors, including further policy changes and inventor behavior. However, there is certainly reason to believe that the incentive to do R\&D will be affected by patent policy. For example, Aoki and Spiegel (1998) present a theoretical model predicting that early disclosure would lead to fewer innovations. Unfortunately, there is little empirical evidence available as to what the effect might be. Thus, rather than assume values for changes in behavior, we ask the following question: what changes are necessary to cancel out the gains of early disclosure?

We first look at the effect of early disclosure on the propensity to patent. One concern of opponents of early disclosure is that it will increase the use of trade secrets, rather than patents, as a means of intellectual property protection. Thus, we ask how much the propensity to patent must fall to offset the benefits of early disclosure. If innovators reduce their affected applications 
(applications which would take longer than 18 months to grant) by more than 4.25 percent per year, the projected gains of the policy over the baseline disappear. ${ }^{29}$

On the other hand, if the information in ungranted patent applications is valuable to follow-on inventions, any negative effects of a fall in the propensity to patent may be counteracted. Unfortunately, it is impossible at this point to estimate the value of the knowledge imparted by published patent applications that will never be granted. That knowledge is entirely new, as it would never have been released under the previous system. ${ }^{30}$ For example, if they add five percent to the new knowledge stock added each year, they cancel out indefinitely the negative repercussions of a 4.25 percent drop in applications due to secrecy concerns.

Therefore, the primary message of these simple "what-if" projections is one of a potentially large positive impact in patent grants over the first few decades, followed by a return to the same long-run path of patent activity. We suggest that the policy change may be encouraging a short-term boost to patent levels, rather than a permanent boost in long-term speed. Naturally, that result is sensitive to a host of other factors, including any change in the propensity to patent and the exact size of the gains from publishing nongranted patent applications. More research on the link between changes in patent protection and inventive behavior would naturally help to clarify these projections.

\footnotetext{
${ }^{29}$ To test this possibility, we considered a subset of our data, using all U.S. patents granted to American applicants with a priority date of 1980,1983, 1985 or 1990 (for a total of 313,983 documents). There is an unsurprisingly clear positive relationship between our measure of value (citations to a patent) and the probability of patenting abroad. However, controlling for citations, there is no evidence that patents with a long grant lag are less likely to patent abroad. In fact, there is a robust counterintuitive positive relationship between grant lag and patenting abroad, holding true across sectors, over time, and across different definitions of the citation variable designed to combat collinearity. Thus, our results imply that the added secrecy of the U.S. system may have had little impact on the incentives of U.S. inventors to apply for protection in multiple nations. Since these results only apply to the marginal decision to patent elsewhere once a patent has been granted in the U.S., they infer nothing about whether the level of R\&D will change, or whether inventors will prefer to hold trade secrets instead of any patent at all.

${ }^{30}$ It is theoretically available in other nations which have published applications, but collection of these data would involve manual examination of patent documents, as only the U.S. Patent Office has electronically recorded this element of each patent record.
} 


\section{Conclusions and Policy Implications}

There has been great concern among inventor advocacy groups that the recent decision to publish all American patent applications after eighteen months would adversely affect inventions, and in particular, would slow the rate of discovery of important inventions. Using patent data from the last twenty years, we find that most patents will face earlier disclosure under the proposed laws, as less than thirty percent of all patent applications in the U.S. are granted within 18 months of the initial application. Furthermore, we find that larger inventions, as measured by subsequent citations, have a longer lag between application and grant. Therefore, large (highly cited) inventions will face earlier disclosure more frequently and by a greater degree than will the average patent.

The net effect of the proposed policy on the incentives to patent depend on the exact parameter estimates, with faster diffusion via published patents weighing against a possible increased reluctance to patent due to reduced secrecy. Looking at patent citation data, we find evidence that faster knowledge diffusion will be a benefit of early publication. Finally, we simulate the potential gains from faster diffusion under a best-case scenario, and find that patenting may increase significantly in the short-run, but that the long-run effects are negligible. In fact, any gains from faster diffusion may be offset if innovative activity, or the propensity to patent, falls by just 4.25 five percent due to any perceived decreased value of patent protection. 


\section{References}

“The Law on Patents: Save the Little Guy," The Economist, September 20, 1997, p. 30.

Aoki, Reiko and Thomas J. Prusa (1996), "Product Development and the Timing of Information Disclosure Under U.S. and Japanese Patent Systems," Journal of the Japanese and International Economies, 10(3), pp. 233-249.

Aoki, Reiko and Yossi Spiegel (1998), "Pubic Disclosure of Patent Applications, R\&D, and Welfare," The Foerder Institute for Economic Research Working Paper No. 30-98, Tel Aviv University.

Bloch, Francis and Paul Markowitz (1996), "Optimal disclosure delay and multistage R\&D competition,” International Journal of Industrial Organization, Vol 14, pp. 159-179.

Blount, Steve, (1999) "The use of Delaying Tactics to Obtain Submarine Patents and Amend Around A Patent that A Competitor has Designed Around," Journal of the Patent and Trademark Office Society, 81(1) pp. 11-32.

Caballero, Ricardo J. and Adam B. Jaffe (1993), "How High are the Giants' Shoulders: An Empirical Assessment of Knowledge Spillovers and Creative Destruction in a Model of Economic Growth," in Olivier J. Blanchard and Stanley Fischer, eds., NBER Macroeconomics Annual 1993, MIT Press, Cambridge, MA.

Eaton, Jonathan and Samuel Kortum (1999), "International Technology Diffusion: Theory and Measurement," International Economic Review, 40, 537-570.

Greene, William H. (1993), Econometric Analysis, Macmillan Publishing Company, New York.

Griliches, Zvi (1990), "Patent statistics as economic indicators," Journal of Economic Literature, $28,1661-1707$.

Jaffe, Adam B., Michael S. Fogarty, and Bruce A. Banks (1998), "Evidence from Patents and Patent Citations on the Impact of NASA and Other Federal Labs on Commercial Innovation," Journal of Industrial Economics, 46, 183-205.

Jaffe, Adam B., Rebecca Henderson and Manuel Trajtenberg (1993), "Geographic Localization of Knowledge Spillovers as Evidenced by Patent Citations," Quarterly Journal of Economics, 108, 577-598.

Jaffe, Adam B. and Manuel Trajtenberg (1996) "Flows of Knowledge From Universities and Federal Labs: Modeling the Flow of Patent Citations Over Time and Across Institutional and Geographic Boundaries,” NBER Working Paper \#5712.

Kortum, Samuel and Josh Lerner (1998), "Stronger Protection or Technological Revolution: What is Behind the Recent Surge in Patenting?" Carnegie-Rochester Conference Series on Public Policy, 48, pp. 247-304. 
Lanjouw, Jean O., Ariel Pakes and Jonathan Putnam (1996), "How to Count Patents and Value Intellectual Property: Uses of Patent Renewal and Application Data," NBER Working Paper \#5741.

Lanjouw, Jean O. and Mark Schankerman (1999), “The Quality of Ideas: Measuring Innovation with Multiple Indicators," NBER Working Paper \#7345.

Montgomery, Rick (1998), "Patent fight pits business vs. little guy," The Kansas City Star, March 30, 1998, A1,A10.

Ordover, Janusz A. (1991), “A Patent System for Both Diffusion and Exclusion,” Journal of Economic Perspectives, 5, 43-60.

Pakes, Ariel and Margaret Simpson (1989), "Patent Renewal Data," Brookings Papers: Microeconomics, 331-410.

Popp, David (1997), Induced Innovation, Energy Prices, and the Environment, Ph.D. Thesis, Yale University.

Putnam, Jonathan (1996), The Value of International Patent Protection, Ph.D. Thesis, Yale University.

Trajtenberg, Manuel (1990), "A Penny for Your Quotes: Patent Citations and the Value of Innovations," Rand Journal of Economics, 21, 172-187. 
Figure 1 - Sample Patent Application

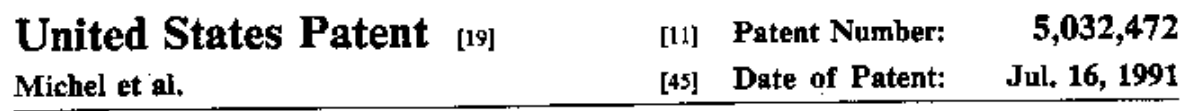

[54] FILMS OF CATENATED PHOSPHORUS MATERIAIS, THEIR PREPARATION AND USE, AND SEMICONDUCTOH AND OTHER DEVICES EMPLOYTNG THEM

[75] Inventors: Chrigtion G. Michel, Ossinirigg; Rozalle Schathter, New York, both Rozalie Schachter, Neur York,
of W.Y.; Mark A. Kuck, Upper Montclair, $N_{4} J_{;}^{\prime}$ John A. Baumind, Dobbs Ferry, N.Y,; Poul M. Racegh, Chicago, III.

[73] Assignes: Stanter Chemleal Compny, Westport, Conn.

[21] ApFl. No.: 322,689

(22] Filed: Mar. 13, 1999

Related U.S. Applifention Dota

[60] Division of Str. No, 660,367, Dec 11, 1984, Pat. No. 4,818,636, and a enntinuation-in-part of Ser. No. 9 60 , 587, Jul. 16, 1986, Pat. No. 4,746,500, Ser. No. 796,429, Nov. 8, 1985, Pat. No. 4,732,659, Ser. No. 736,750 , May 2L, 19\%, Pat. No 4,696,928, Ser. No. 695,255 , Jan. 28, 1985, Pat. No 4,678,266, Ser No. 695,268 Jan. 28, 1965 , abandoned, Ser. No. 619,053 , 195, 208, 10.4, Pat. No, 4,558,340, Ser. No. 381,101, Jun. 11, 1984, Pat. No, 4,538,40, Ser. No. 581,102, Frb. 17, 1984. Pat. No, 4,613,445, Ser. No, 98,102, Feb. $[7,1984$, Ser. No. 581, 103 , Feb. 17, 1984, abandoned. Ser. No. 5 B, 104, Feh. 17, 1984, abandoned, Sier. No. 581, 105, Feb. 17, 1994, Pat. No. 4,618,343, Ser. No. 9.4 L l l, Feb. 17, 1994, abandaned, Ser. No. 591,139, Feb. 17, 1984, Fet, No, 4,649,024, Ser. No. Fob 17, 1984, abardoned, Ser. No. sq9,157, Jun. 29, 1983 abondoned, Str. No 569.158, Jum, 29, 1983, Pat No. 4,591,409, Ser. No, 509, 159 , Jur. 29, 1983, Pat. No. 4,596, J21, 5tr, No. 505, 175, Jun. 29, 1983 , Fat. No. 4,509, C65, and Ser. No. 509,210. Jurn, 29, 1981, Pat, No. $4,567,503$, said SEr. No, 6 50,367 , is a divition of Ser.

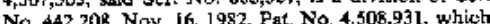
No. 4t2

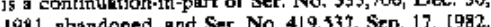

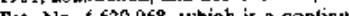

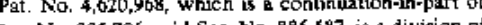
Ser. No. 335,706, said Ser. No. 886,997, is a division of Ser. No. 581,101, said Ser. No. 796,429, is a division of Ser. No. 519,053 , and a continution-in-part of Ser.
No, 509,175 , and Str. No. 42,208, seid Ser. No. 736.750 .

[1] Int $\mathrm{Cl}^{5}$

[52] U.s. Cl. ........................ 428/704, $428 / 432$; [58] Field of Stureh ........... 428/704, 432, 469, 472.3

[56] References Cited U.S. PATENT DOCUMENTS

$4,309,066 \quad 4 / 1985$ Sehachter et al. .................. 428/432 $4,567,507 \quad 1 / 1986$ olezo et al. ,...................... 357/54 4,596,721 6/19:36 Brock et al. ......................14 427/82 4,619,345 lo/1986 Tuck ex al. . ................. 23/293 $\mathrm{R}$

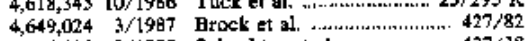

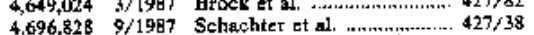

Brimary Examiner-George F. Lesmes

Assigtair Exominar-Jill M. Gray

Atromey, Agentr or Firm-F. Eugene Davia, IV

[5T] ABSTRACT

High phosphorus polyphosphides, namely $\mathbf{M P}_{\boldsymbol{x}}$ where $M$ is an alkati metel $(L, N a, K, R b$, and $C s)$ or metals mimicking the bonding behawior of an alkali metal, and $x=7$ to 15 or wery much greater than 15 (new forms of phosphorus) are useful semiconductors in their crystalline, polyctystalline and amorphous forms (boules and films). MPis appears to have the best properties and $\mathbf{K P}_{15}$ is the easiet to synthesize $\mathbf{F}$ may include other pnictides as well ts other trivalent atomie species. Resistance lowering mey be aceomplished by doping with $\mathrm{Ni}, \mathrm{Fe}, \mathrm{Cr}$, and othet metals having secupied $\mathrm{d}$ or $f$ onter electronic levels; or by incorporation of As and other prictides. Top contects forming junction devices doped with $\mathrm{Ni}$ and employing $\mathrm{Ni}$ as a back sontact comprise Cu, Al, Mg, Ni Au, Ag, and Ti. Pholovoltaic, photoresistive, and photoluminescent devices are also disclosed. All semiconductor applications appear iessible.

These semiconductors belorig to the class of polymer forming, trivalent atomic species forming homatomie, covalent bonds havìng a coordination number slightly les thath 3. The predominant local order appears to be alt parallel pentagonal tubes in all forms, including anorphous, except for the monoclitic and twisted fiber ellotropes of phosphorus.

\section{(Abstract continued on rext page-)}

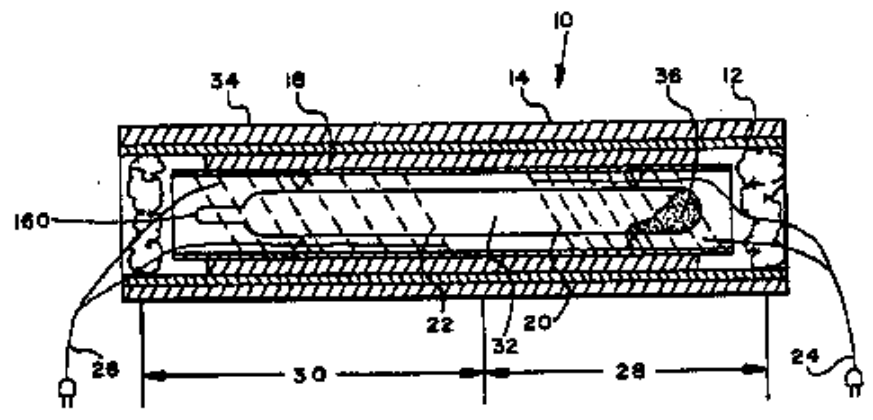


Figure 2 - Distribution of Lags between Application and Grant - All U.S. Patents

Grant lag frequency

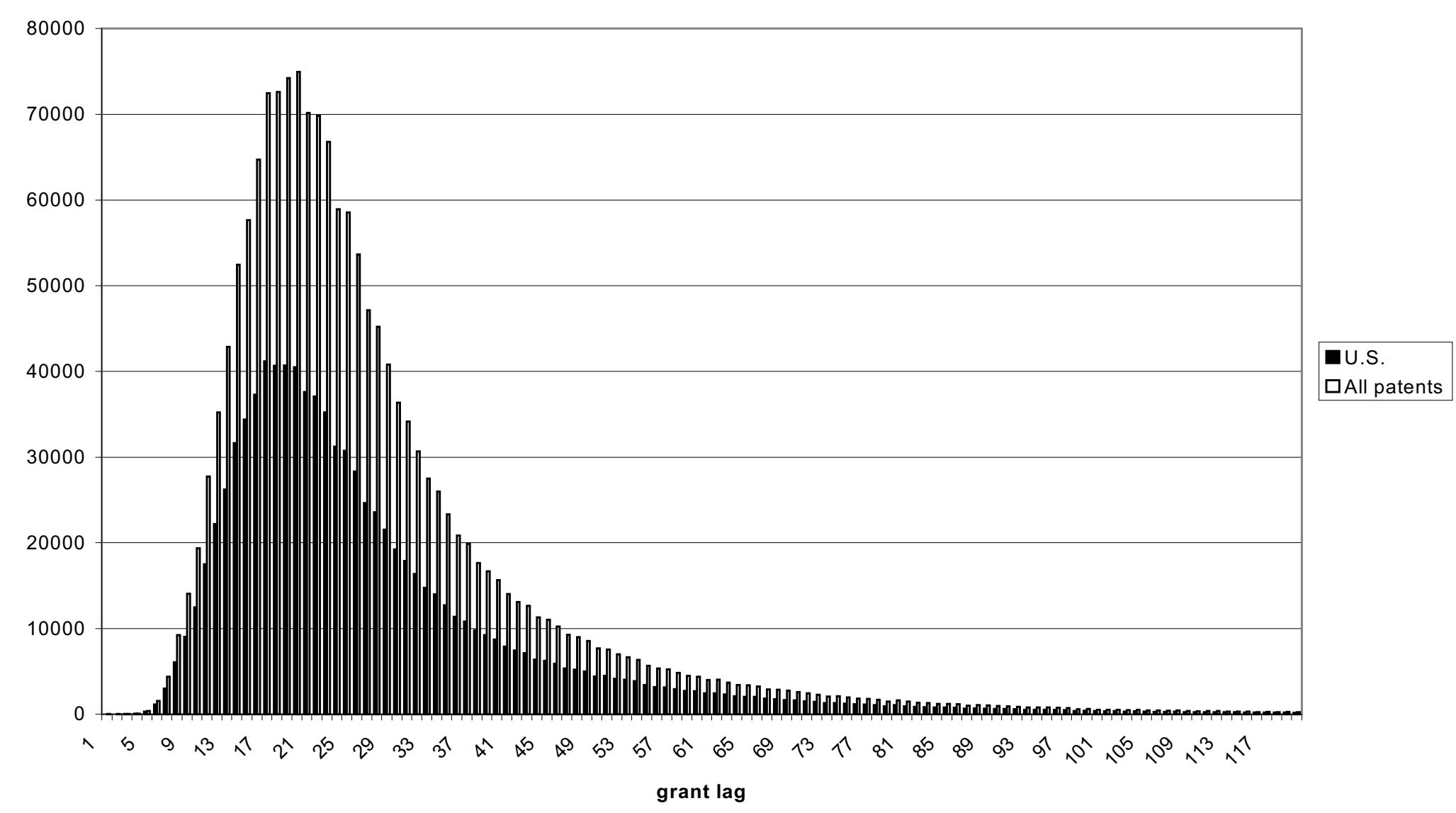


Figure 3 - Percentage of Patents Granted Within 18 months of First Related Application

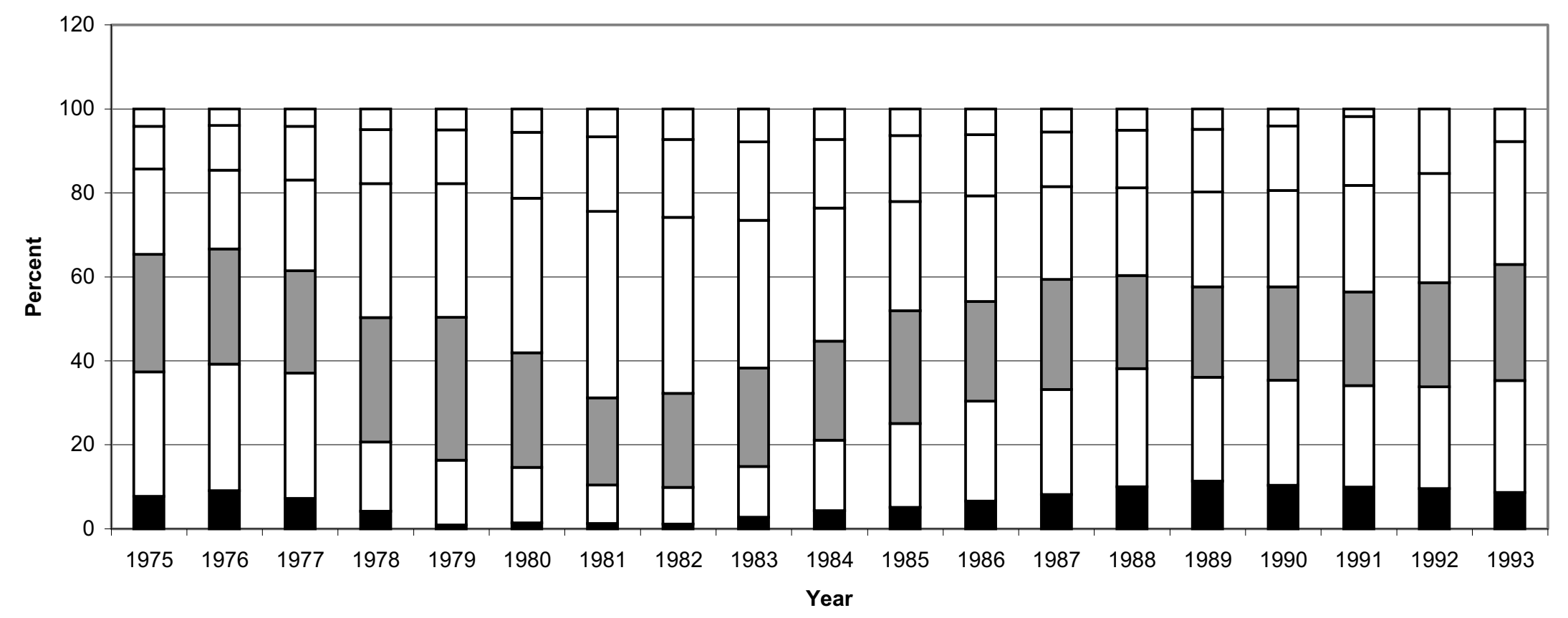

$\mathbf{0}<=12$ months $\quad \square 13-18$ months $\quad \square 19-24$ months $\quad \square 25-36$ months $\quad \square 36-60$ months $\quad \square>60$ montr 


\section{Figure 4 - Effect of Grant Lag on the Probability of Citation}

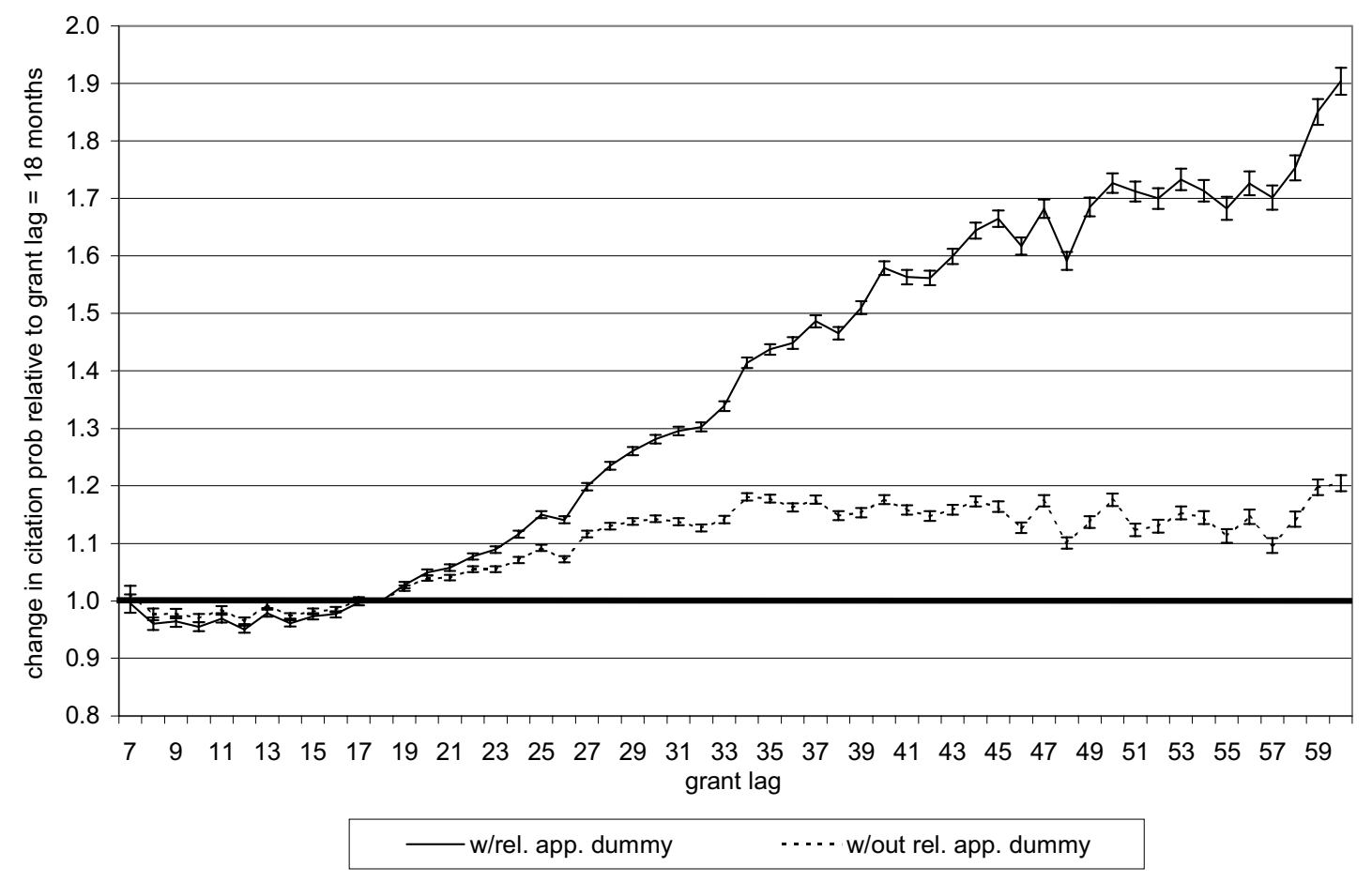

The figure shows the change in the probability of citation for patents with different grant lags. Grant lags of 18 months are normalized to one. Bars show $+/$ - one standard error. 
Figure 5 - Does Publication Aid Diffusion?

Case A: Diffusion begins after publication
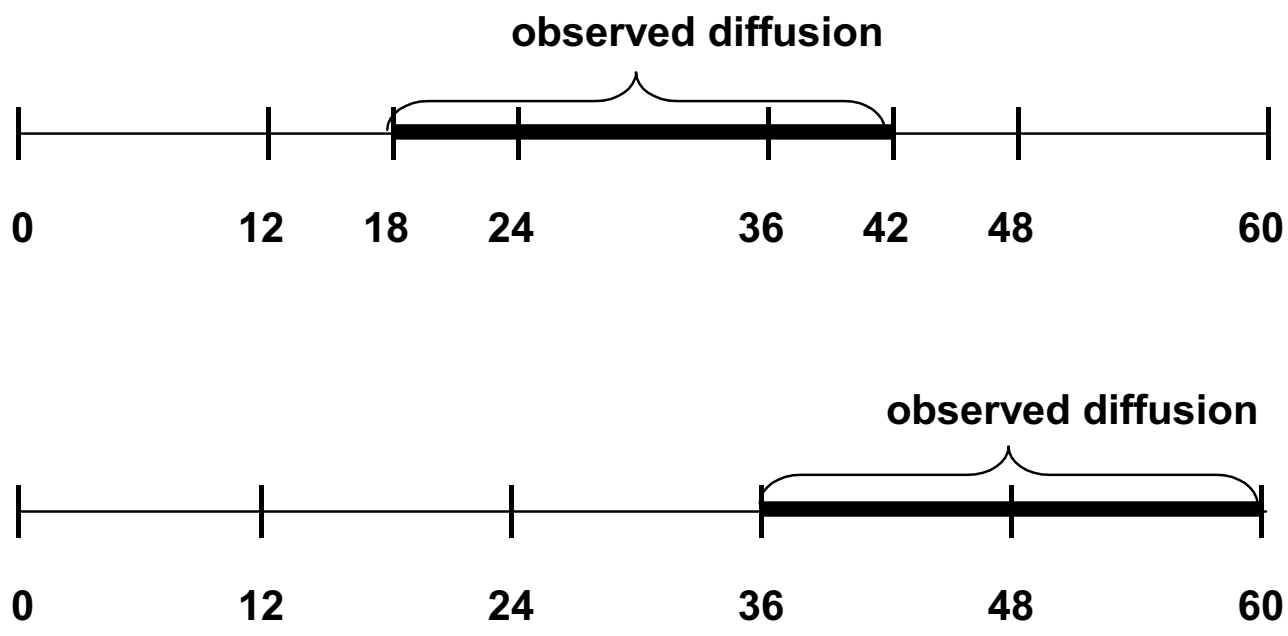

Case B: Diffusion begins at application
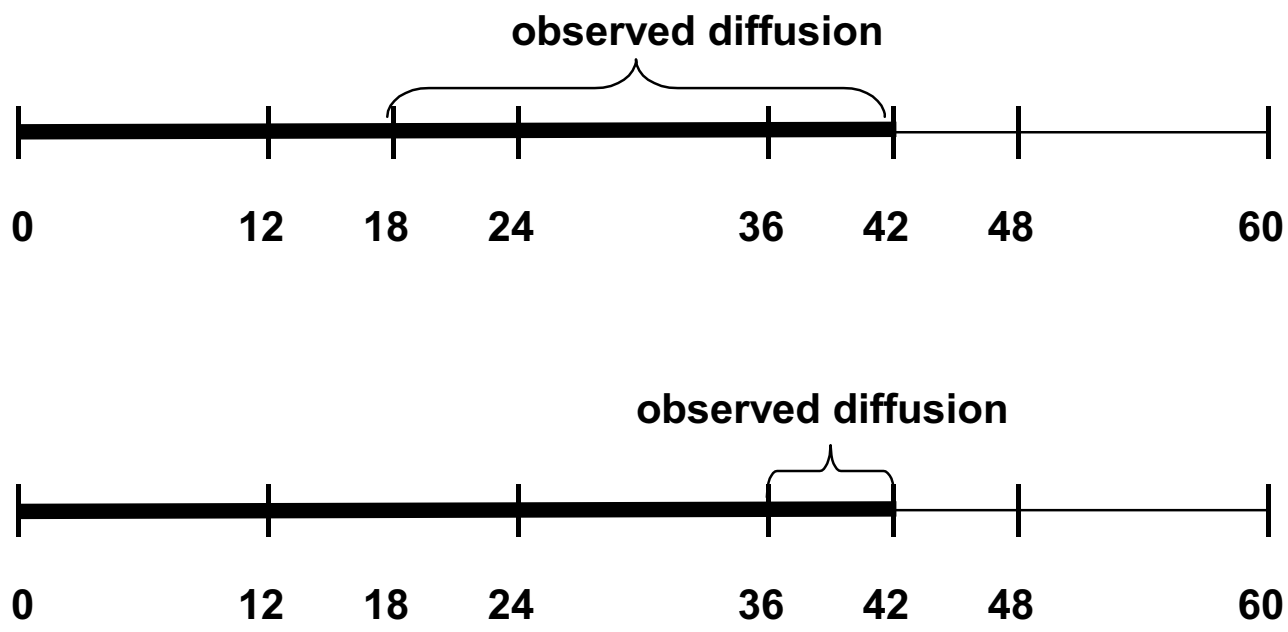

Figure 5 compares the actual time of diffusion to what is observed in the data. Each line represents a timeline from the date of application. The dark bar represents actual diffusion activity, which is assumed to take the same amount of time for each patent. Diffusion observed from the date of grant is denoted with brackets. For each case, the top line represents a patent granted after 18 months, and the bottom line is a patent granted after 36 months. Case A shows that when diffusion begins after publication of a patent, the observed rate of diffusion is the same for both patents. However, if diffusion begins from the filing of the application, the observed diffusion is shorter for the patent with the longer grant lag. 


\section{Figure 6 - Policy Simulation}

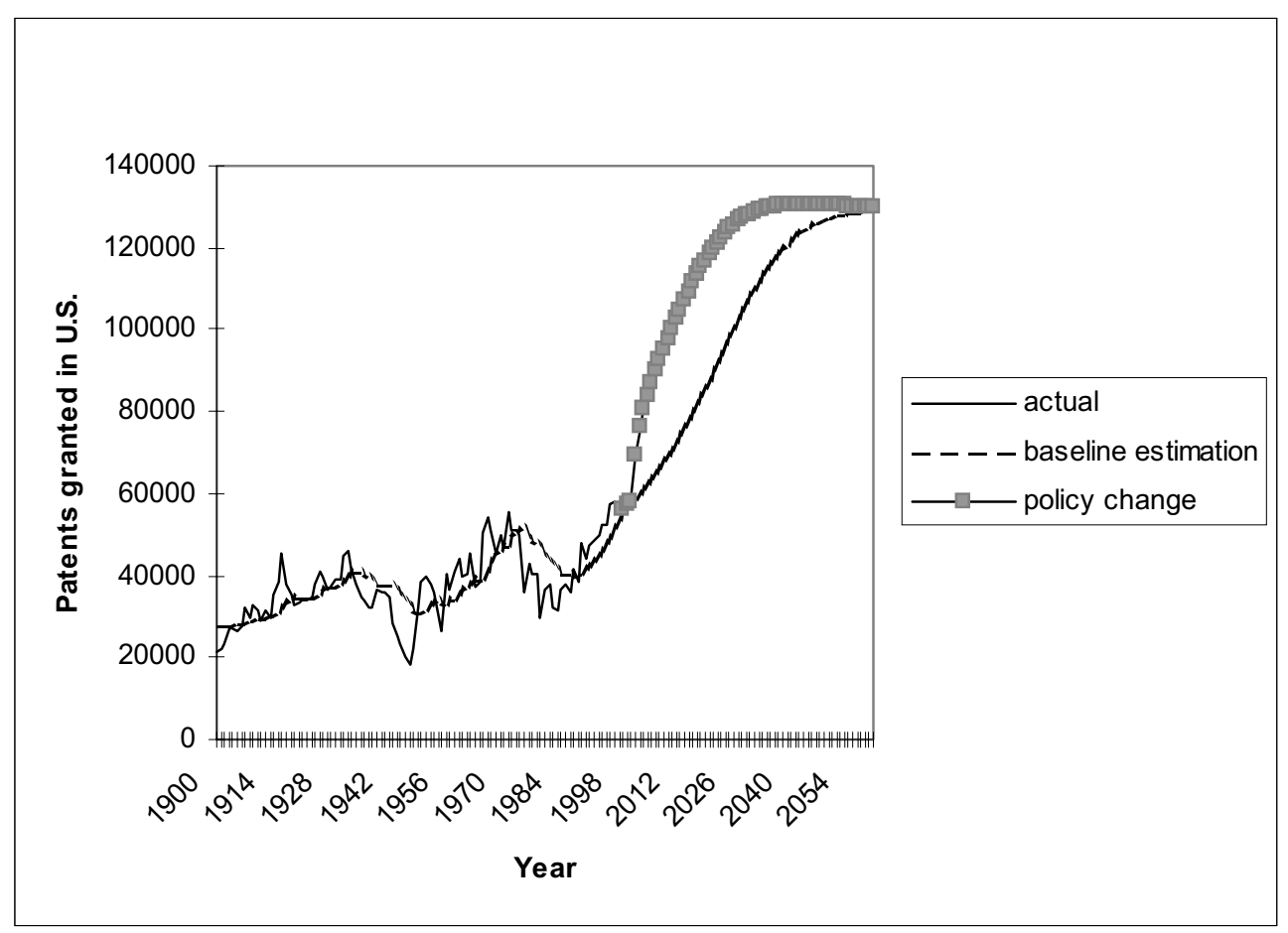

Figure 6 presents actual patent data from 1900-1998, our baseline simulation, and the simulated policy change. Note that early disclosure of patent applications leads to a quick jump in patenting activity, but that the long run effect is small. 


\section{Table 1 - Summary Statistics for Grant Lags}

Number of patents granted

\begin{tabular}{lrrrr}
\hline \hline & & & Domestic $\%$ Domestic \\
Technology Group & All Patents & $\begin{array}{r}\text { Domestic } \\
\text { Applicants }\end{array}$ & Applications & Applications \\
\hline 1. Medical/Biochemistry & 134,805 & 83,914 & 32,125 & $38 \%$ \\
2. Other Chemical & 337,844 & 187,880 & 69,546 & $37 \%$ \\
3. Electronics & 329,037 & 167,490 & 34,701 & $21 \%$ \\
4. Mechanical & 245,374 & 126,922 & 28,693 & $23 \%$ \\
5. Engineering/Physics & 393,343 & 226,897 & 43,831 & $19 \%$ \\
6. Others & 213,589 & 136,956 & 26,380 & $19 \%$ \\
\hline Overall & $1,653,992$ & 930,059 & 235,276 & $25 \%$ \\
\hline \hline
\end{tabular}

Mean lag between application and grant, in months

\begin{tabular}{lrrrr}
\hline \hline Technology Group & All Patents & $\begin{array}{r}\text { Domestic } \\
\text { Applicants }\end{array}$ & $\begin{array}{r}\text { Original } \\
\text { Domestic } \\
\text { Applications }\end{array}$ & $\begin{array}{r}\text { Domestic } \\
\text { with Related } \\
\text { Applications }\end{array}$ \\
\hline 1. Medical/Biochemistry & 34.94 & 35.33 & 24.28 & 53.14 \\
2. Other Chemical & 31.15 & 32.15 & 22.53 & 48.51 \\
3. Electronics & 29.61 & 30.25 & 25.42 & 48.73 \\
4. Mechanical & 26.01 & 26.52 & 21.37 & 44.14 \\
5. Engineering/Physics & 25.94 & 26.09 & 21.64 & 44.69 \\
6. Others & 24.88 & 24.77 & 20.29 & 43.55 \\
\hline Overall & 28.34 & 28.76 & 22.46 & 47.38 \\
\hline \hline
\end{tabular}

Median lag between application and grant, in months

\begin{tabular}{lrrrr}
\hline \hline & & $\begin{array}{r}\text { Original } \\
\text { Domestic }\end{array}$ & $\begin{array}{r}\text { Domestic } \\
\text { Domestic } \\
\text { with Related }\end{array}$ \\
Technology Group & All Patents & Applicants & Applications & Applications \\
\hline 1. Medical/Biochemistry & 28 & 28 & 22 & 47 \\
2. Other Chemical & 25 & 25 & 20 & 41 \\
3. Electronics & 25 & 25 & 23 & 43 \\
4. Mechanical & 22 & 22 & 20 & 39 \\
5. Engineering/Physics & 22 & 22 & 20 & 39 \\
6. Others & 21 & 21 & 19 & 38 \\
\hline Overall & 23 & 23 & 20 & 41 \\
\hline \hline
\end{tabular}

Modal lag between application and grant, in months

\begin{tabular}{|c|c|c|c|c|}
\hline Technology Group & All Patents & $\begin{array}{r}\text { Domestic } \\
\text { Applicants }\end{array}$ & $\begin{array}{r}\text { Original } \\
\text { Domestic } \\
\text { Applications }\end{array}$ & $\begin{array}{r}\text { Domestic } \\
\text { with Related } \\
\text { Applications }\end{array}$ \\
\hline 1. Medical/Biochemistry & 20 & 20 & 20 & 38 \\
\hline 2. Other Chemical & 20 & 17 & 17 & 34 \\
\hline 3. Electronics & 20 & 20 & 20 & 39 \\
\hline 4. Mechanical & 19 & 18 & 18 & 34 \\
\hline 5. Engineering/Physics & 20 & 17 & 17 & 34 \\
\hline 6. Others & 17 & 17 & 17 & 32 \\
\hline Overall & 20 & 17 & 17 & 34 \\
\hline
\end{tabular}




\section{Table 2 - Distribution of Grant Lags by Technology}

\% of Domestic Applications granted within:

\begin{tabular}{lrrr}
\hline \hline Technology group & & $19-30$ & $\begin{array}{r}31+ \\
\text { 1. Medical/Biochemistry }\end{array}$ \\
2. Other Chemical & $19.51 \%$ & $36.10 \%$ & $44.39 \%$ \\
3. Electronics & $27.56 \%$ & $35.55 \%$ & $36.88 \%$ \\
4. Mechanical & $34.50 \%$ & $41.55 \%$ & $33.95 \%$ \\
5. Engineering/Physics & $33.00 \%$ & $40.81 \%$ & $25.19 \%$ \\
6. Others & $33.74 \%$ & $43.08 \%$ & $23.18 \%$ \\
Overall & $39.56 \%$ & $39.52 \%$ & $20.92 \%$ \\
\hline \hline
\end{tabular}


Table 3 - Regression Results -Dependent Variable: Probability of Citation

\begin{tabular}{|c|c|c|c|}
\hline Parameter & Estimate & $\begin{array}{r}\text { Standard } \\
\text { Error }\end{array}$ & $\begin{array}{r}\text { T-ratio } \\
\left(H_{0} \beta=1\right)\end{array}$ \\
\hline grant lag $<=18$ months & 1.000 & $\mathrm{~N} / \mathrm{A}$ & $\overline{N / A}$ \\
\hline grant lag > 18 months & 1.212 & 0.004 & 55.15 \\
\hline no related application & 1.000 & N/A & $\mathrm{N} / \mathrm{A}$ \\
\hline related application & 0.700 & 0.003 & -114.47 \\
\hline year cited 1976-1977 & 1.000 & N/A & $\mathrm{N} / \mathrm{A}$ \\
\hline year cited 1978-1979 & 1.108 & 0.008 & 14.03 \\
\hline year cited 1980-1981 & 1.182 & 0.010 & 17.86 \\
\hline year cited 1982-1983 & 1.339 & 0.014 & 23.69 \\
\hline year cited 1984-1985 & 1.520 & 0.020 & 26.40 \\
\hline year cited 1986-1987 & 1.822 & 0.028 & 28.94 \\
\hline year cited 1988-1989 & 2.065 & 0.039 & 27.67 \\
\hline year cited 1990-1991 & 2.191 & 0.048 & 24.66 \\
\hline year cited 1992-1993 & 2.268 & 0.058 & 21.71 \\
\hline year cited 1994-1996 & 1.979 & 0.060 & 16.40 \\
\hline year citing 1977-1978 & 1.000 & $\mathrm{~N} / \mathrm{A}$ & $\overline{N / A}$ \\
\hline year citing 1979-1980 & 0.876 & 0.018 & -7.03 \\
\hline year citing 1981-1982 & 0.772 & 0.015 & -15.08 \\
\hline year citing 1983-1984 & 0.657 & 0.013 & -25.80 \\
\hline year citing 1985-1986 & 0.612 & 0.013 & -29.58 \\
\hline year citing 1987-1988 & 0.603 & 0.014 & -28.77 \\
\hline year citing 1989-1990 & 0.605 & 0.015 & -26.00 \\
\hline year citing 1991-1992 & 0.582 & 0.016 & -25.80 \\
\hline year citing 1993-1994 & 0.617 & 0.019 & -20.07 \\
\hline year citing 1995-1996 & 0.697 & 0.024 & -12.62 \\
\hline Medical/Biochemistry & 1.815 & 0.009 & 87.22 \\
\hline Other Chemical & 1.146 & 0.006 & 24.67 \\
\hline Electronics & 1.615 & 0.008 & 80.83 \\
\hline Mechanical & 0.852 & 0.005 & -27.32 \\
\hline Engineering/Physics & 1.032 & 0.005 & 6.14 \\
\hline Other Technology Groups & 1.000 & $\mathrm{~N} / \mathrm{A}$ & $\mathrm{N} / \mathrm{A}$ \\
\hline citing country is U.S. & 1.000 & N/A & $\mathrm{N} / \mathrm{A}$ \\
\hline citing country is Japan & 0.389 & 0.002 & -266.71 \\
\hline citing country is Germany & 0.341 & 0.004 & -178.50 \\
\hline citing country is France & 0.445 & 0.006 & -94.47 \\
\hline citing country is U.K. & 0.533 & 0.006 & -76.09 \\
\hline citing country is Canada & 0.639 & 0.007 & -49.80 \\
\hline citing country is other EPO & 0.404 & 0.004 & -141.16 \\
\hline citing country is other foreign & 0.446 & 0.005 & -102.45 \\
\hline decay (based on patents) & $4.00 \mathrm{E}-06$ & $3.866 \mathrm{E}-08$ & $103.34^{*}$ \\
\hline diffusion (based on time) & $3.80 \mathrm{E}-06$ & $6.90 \mathrm{E}-08$ & $55.02^{*}$ \\
\hline
\end{tabular}

\begin{tabular}{lr}
\hline \hline${ }^{*}-\mathrm{H}_{0}$ is $\beta=0$ & 32,112 \\
Number of Observations: & 34 \\
Degrees of Freedom - Model & 32,078 \\
Degrees of Freedom - Error & 1.5378 \\
SSE & 0.8387
\end{tabular}


Table 4 - Regression Results -Dependent Variable: Probability of Citation

\begin{tabular}{|c|c|c|c|}
\hline & & Standard & T-ra \\
\hline Parameter & Estimate & Errc & $H_{B} \beta=$ \\
\hline grant lag <= 12 months & 0.948 & 0.004 & -13.72 \\
\hline nt lag $13-18$ months & 1.000 & N/A & $N / A$ \\
\hline 9-24 months & 1.088 & 0.003 & 31.25 \\
\hline $25-30$ months & 1.210 & .003 & 62.80 \\
\hline ths & 1.3 & 0 . & 80.24 \\
\hline$-48 m$ & 1.471 & 0.005 & 97.00 \\
\hline $49-60$ months & 1.525 & 0.007 & 77.52 \\
\hline grant lag $>60$ months & 1.358 & 0.006 & 57.83 \\
\hline
\end{tabular}

Number of Observations: $\quad 118,340$

Degrees of Freedom -- Model 40

Degrees of Freedom -- Error $\quad 118,300$

SSE

2.3586

Adjusted R-Square $\quad 0.7737$ 
Table 5 - Do the Rates of Decay and Diffusion Vary by Grant Lag?

\begin{tabular}{lrrr}
\multicolumn{4}{c}{ Panel A: Both Decay and Diffusion Change } \\
\hline \hline & & Standard & T-ratio \\
\multicolumn{1}{c}{ Parameter } & Estimate & Error & $\left(\mathbf{H}_{\mathbf{0}} \beta=\mathbf{0}\right)$ \\
\hline Decay (grant lag $<=12$ months) & $4.03 \mathrm{E}-06$ & $3.73 \mathrm{E}-08$ & 107.99 \\
Decay (grant lag $>24$ months) & $3.82 \mathrm{E}-06$ & $2.91 \mathrm{E}-08$ & 131.24 \\
Diffusion (grant lag $<=12$ months) & $4.29 \mathrm{E}-06$ & $7.18 \mathrm{E}-08$ & 59.72 \\
Diffusion (grant lag $>24$ months) & $4.07 \mathrm{E}-06$ & $6.27 \mathrm{E}-08$ & 64.87 \\
\hline F-statistic: & & & 29.84 \\
\hline \hline
\end{tabular}

Number of Observations: $\quad 315,903$

Degrees of Freedom - Model 77

Degrees of Freedom - Error $\quad 315,826$

SSE

5.2916

Adjusted R-Square

0.4397

Panel B: Changing Diffusion Only

\begin{tabular}{lrrr}
\hline \hline & & $\begin{array}{r}\text { Standard } \\
\text { Error }\end{array}$ & $\begin{array}{r}\text { T-ratio } \\
\left(\mathbf{H}_{\mathbf{0}} \boldsymbol{\beta}=\mathbf{0}\right)\end{array}$ \\
\hline Decay & $3.83 \mathrm{E}-06$ & $2.90 \mathrm{E}-08$ & 132.23 \\
Diffusion grant lag $<=18$ & $4.10 \mathrm{E}-06$ & $6.49 \mathrm{E}-08$ & 63.18 \\
Diffusion grant lag $>18$ & $4.10 \mathrm{E}-06$ & $6.31 \mathrm{E}-08$ & 65.01 \\
\hline F-statistic: & & & 0.00 \\
\hline \hline
\end{tabular}

$\begin{array}{lr}\text { Number of Observations: } & 315,903 \\ \text { Degrees of Freedom -- Model } & 76 \\ \text { Degrees of Freedom -- Error } & 315,827 \\ \text { SSE } & 5.2926 \\ \text { Adjusted R-Square } & 0.4396\end{array}$

Table 5 shows the regression results when the rates of decay and diffusion are allowed to vary by the grant lag of the cited patent. The F-statistic in panel A is for the null hypothesis that the two decay rates are equal and that the two rates of diffusion are equal. In panel $\mathrm{B}$, it is for the null hypothesis that the rates of diffusion are equal. Other results are similar to those in section II. 


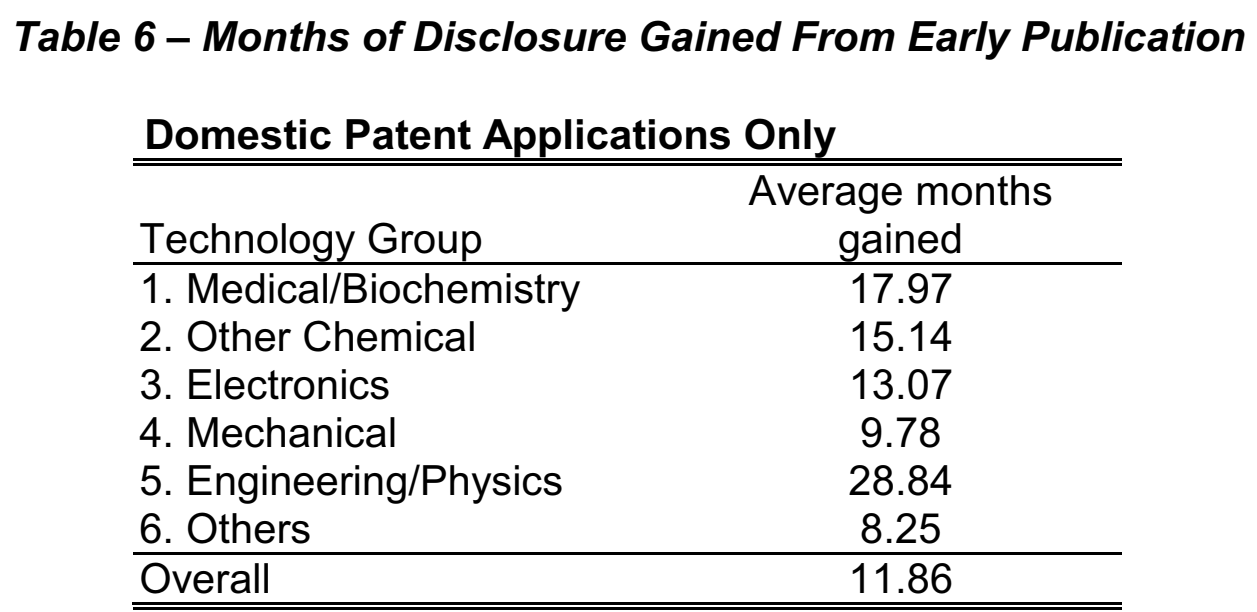

Table 6 shows the average months of disclosure that would be gained by early publication of patent applications in the United States. These are weighted averages based on the distribution of grant lags for each technology group. 